\title{
Biosensors Show the Pharmacokinetics of S-Ketamine in the Endoplasmic Reticulum
}

\author{
Kallol Bera ${ }^{1}$, Aron Kamajaya ${ }^{1}$, Amol V. Shivange ${ }^{1}$, Anand K. Muthusamy ${ }^{1,2}$, \\ Aaron L. Nichols ${ }^{1,2}$, Philip M. Borden ${ }^{3}$, Stephen Grant ${ }^{2}$, Janice Jeon ${ }^{1}$, Elaine Lin ${ }^{1}$, \\ Ishak Bishara ${ }^{1}$, Theodore M. Chin ${ }^{1}$, Bruce N. Cohen ${ }^{1}$, Charlene H. Kim ${ }^{1}$, \\ Elizabeth K. Unger ${ }^{4}$, Lin Tian ${ }^{4}$, Jonathan S. Marvin ${ }^{3}$, Loren L. Looger ${ }^{3}$ and \\ Henry A. Lester ${ }^{1 *}$ \\ 'Division of Biology and Biological Engineering, California Institute of Technology, Pasadena, CA, United States, ${ }^{2}$ Division of \\ Chemistry and Chemical Engineering, California Institute of Technology, Pasadena, CA, United States, ${ }^{3} \mathrm{Janelia}$ Research \\ Campus, Howard Hughes Medical Institute, Ashburn, VA, United States, ${ }^{4}$ Department of Biochemistry and Molecular \\ Medicine, University of California, Davis, Davis, CA, United States
}

OPEN ACCESS

Edited by:

Shai Berlin,

Technion Israel Institute of

Technology, Israel

Reviewed by:

Kenji Hashimoto,

Chiba University, Japan

Randy Franklin Stout,

New York Institute of Technology,

United States

*Correspondence:

Henry A. Lester

lester@caltech.edu

Received: 19 August 2019 Accepted: 22 October 2019

Published: 12 November 2019

Citation:

Bera K, Kamajaya A, Shivange AV, Muthusamy AK, Nichols AL, Borden PM, Grant S, Jeon J, Lin E,

Bishara I, Chin TM, Cohen BN, Kim $C H$, Unger EK, Tian L,

Marvin JS, Looger LL and Lester HA (2019) Biosensors Show the

Pharmacokinetics of S-Ketamine in the Endoplasmic Reticulum. Front. Cell. Neurosci. 13:499. doi: 10.3389/fncel.2019.00499
The target for the "rapid" ( $<24 \mathrm{~h}$ ) antidepressant effects of S-ketamine is unknown, vitiating programs to rationally develop more effective rapid antidepressants. To describe a drug's target, one must first understand the compartments entered by the drug, at all levels-the organ, the cell, and the organelle. We have, therefore, developed molecular tools to measure the subcellular, organellar pharmacokinetics of S-ketamine. The tools are genetically encoded intensity-based S-ketamine-sensing fluorescent reporters, iSKetSnFR1 and iSKetSnFR2. In solution, these biosensors respond to S-ketamine with a sensitivity, S-slope $=\operatorname{delta}\left(F / F_{0}\right) /($ delta[S-ketamine] $)$ of 0.23 and $1.9 / \mu \mathrm{M}$, respectively. The iSKetSnFR2 construct allows measurements at $<0.3 \mu \mathrm{M}$ S-ketamine. The iSKetSnFR1 and iSKetSnFR2 biosensors display $>100$-fold selectivity over other ligands tested, including R-ketamine. We targeted each of the sensors to either the plasma membrane (PM) or the endoplasmic reticulum (ER). Measurements on these biosensors expressed in Neuro2a cells and in human dopaminergic neurons differentiated from induced pluripotent stem cells (iPSCs) show that S-ketamine enters the ER within a few seconds after appearing in the external solution near the PM, then leaves as rapidly after S-ketamine is removed from the extracellular solution. In cells, S-slopes for the ER and PM-targeted sensors differ by $<2$-fold, indicating that the ER [S-ketamine] is less than 2-fold different from the extracellular [S-ketamine]. Organelles represent potential compartments for the engagement of S-ketamine with its antidepressant target, and potential S-ketamine targets include organellar ion channels, receptors, and transporters.

Keywords: antidepressants, organelles, green fluorescent protein, protein engineering and design, periplasmic binding proteins (PBPs), inside-out pharmacology, iSketSnFR1, iSketSnFR2 


\section{INTRODUCTION}

Despite half a century of research and improvement, antidepressant drugs do not work optimally. Although selective serotonin reuptake inhibitor antidepressants help appreciable numbers of patients, their benefits appear too slowly (2-6 weeks) after treatment has begun. In contrast, administration of a single, relatively small (subanesthetic) dose of racemic ketamine for $\sim 1 \mathrm{~h}$ partially relieves depression in $<1$ day; this relief continues for several days post-administration (Berman et al., 2000). In some preclinical studies, R-ketamine has more potent and lasting antidepressant action than S-ketamine (Hashimoto, 2019). Recently, the US FDA approved inhaled S-ketamine for treatment-resistant depression.

However, because higher doses of S-ketamine have adverse effects, developing antidepressants that act similarly to S-ketamine may be a better strategy than using S-ketamine itself. To enable developing better rapidly acting antidepressants, one must first understand the mechanism of S-ketamine action, including the molecular target.

Most investigators emphasize the hypothesis that S-ketamine exerts its antidepressant effects by binding to an N-MethylD-aspartate (NMDA) receptor subtype (MacDonald et al., 1991; Blanpied et al., 1997; Preskorn et al., 2008; Autry et al., 2011; Emnett et al., 2013; Gideons et al., 2014; Miller et al., 2014; Johnson et al., 2015). Other articles suggest the following receptor, channel, or transporter targets for ketamine: $\alpha 3 \beta 2$ nicotinic receptors (nAChRs; Lee et al., 2012), $\alpha 4 \beta 2$ nAChRs (Buisson and Bertrand, 1998), $\alpha 7$ nAChRs (Coates and Flood, 2001; Moaddel et al., 2013), dopamine D2 receptors (Kapur and Seeman, 2001, 2002; Seeman and Kapur, 2003), HCN1 channels (Chen et al., 2009), 5-HT2 receptors (Frohlich and Van Horn, 2014), or 5-HT3 receptors (Yamakura et al., 2000). Most contemporary psychiatric drugs have wellestablished receptor, channel, or transporter targets. In contrast, the "target" for the antidepressant actions of S-ketamine is poorly understood.

We comment similarly that downstream signaling pathways are poorly understood. Suggested pathways include mechanistic target of rapamycin (mTOR; Zoncu et al., 2011; Moaddel et al., 2013; Miller et al., 2014), eukaryotic elongation factor 2 (EEF2) kinase (Autry et al., 2011; Gideons et al., 2014; Adaikkan et al., 2018), serine/threonine kinase glycogen synthase kinase-3 (GSK-3; Beurel et al., 2011; Liu et al., 2013), calcium/calmodulindependent protein kinase II (CaMKII; Adaikkan et al., 2018), brain-derived neurotrophic factor (BDNF; Lepack et al., 2014), Kir4.1-containing transport vesicles (Stenovec et al., 2019), and G-protein translocation to/from lipid rafts (Wray et al., 2018). These molecules are thought to participate in enhancements of glutamatergic (Zanos et al., 2018), cholinergic, or GABAergic (Widman and McMahon, 2018) transmission (Ren et al., 2016). Finally, we comment similarly about brain regions and nuclei. Most studies focus on hippocampus and cortex; but ketamine also blocks bursting in the lateral habenula (Yang et al., 2018).

If one does not know the target for a drug, then an appropriate step is to seek that target in all compartments that contain the drug, and to measure how long the drug remains in each compartment. A previous report shows that a ketamine analog enters cells (Emnett et al., 2016). This report presents the first quantitative, dynamically resolved measurements of S-ketamine in an organelle: the endoplasmic reticulum (ER).

To conduct these experiments, we executed a research strategy resembling our previous report for nicotine (Shivange et al., 2019). We developed a genetically encoded fluorescent biosensor for S-ketamine. We targeted the biosensor to either the plasma membrane (PM) or the ER. We then performed fluorescence measurements to dynamically report the S-ketamine concentration in each compartment.

\section{MATERIALS AND METHODS}

\section{Directed Evolution of iSKetSnFR Proteins Using Bacterial-Expressed Protein Assays}

Starting with the iNicSnFR biosensor constructs (Shivange et al., 2019), we constructed and measured $\sim 3,000$ mutants, in iterative rounds of site-saturated mutagenesis (SSM). We utilized the Quikchange mutagenesis protocol (Agilent), including a mixture of three primers, creating 22 unique codons encoding the 20 canonical amino acids (Kille et al., 2013). The 22-codon procedure yields an estimated $>96 \%$ residue coverage for a collection of 96 randomly chosen clones.

A Tecan Spark M10 96-well fluorescence plate reader (equipped with appropriate filters) was used to measure resting and $\mathrm{S}$-ketamine-induced fluorescence ( $\mathrm{F}_{0}$ and $\Delta \mathrm{F}$, respectively). Bacterial lysates were tested with excitation at $485 \mathrm{~nm}$ and emission at $535 \mathrm{~nm}$. Promising clones were amplified and sequenced. The most sensitive construct in each round of SSM was used as a template for the next round of SSM.

\section{Measurements on Purified iSketSnFR Constructs}

Biosensors selected for further study were purified with the His 6 sequence included in the bacterial expression vector (Shivange et al., 2019). Proteins were purified by immobilization in

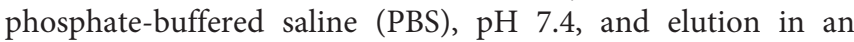
imidazole gradient $(10-200 \mathrm{mM})$. Proteins were concentrated by centrifugation through a $30 \mathrm{kDa}$ cut off column, and by dialysis against PBS. The dialyzed protein was quantified using a nanodrop spectrofluorometer, and 50 or (preferably) $100 \mathrm{nM}$ was used in dose-response studies to characterize responses to various ligands. Dose-response relations for ligands were conducted with the plate reader. The $\mathrm{pH}$-dependent dose-response studies with purified iSketSnFR constructs were performed using $3 \times$ PBS buffers.

\section{Expression in Mammalian Cells}

We constructed two variants of the iSKetSnFR1 and iSketSnFR2 biosensors for expression in mammalian cells. The plasma membrane (_PM) and endoplasmic reticulum (_ER) variants were constructed by a circular polymerase extension cloning procedure. For iSketSnFR1_PM and iSKetSnFR2_PM, we cloned the bacterial constructs into $\mathrm{pCMV}(\mathrm{MinDis})$, a variant of pDisplay (Invitrogen, Carlsbad, CA, USA) lacking the 
hemagglutinin tag (Marvin et al., 2013). We modified the previous transmembrane domain (Shivange et al., 2019) as follows. We replaced the terminal KKPR of the PDGF receptor (a putative ER retention motif) with KYLQKRRERRRQ (a p14 Golgi export motif) and ENANSFCYENEVAL (a putative Kir2.X ER export motif). To generate iSketSnFR1_ER and iSketSnFR2_ER, we replaced the 14 C-terminal amino acids (QVDEQKLISEEDLN, including the Myc tag) with an ER retention motif, QTAEKDEL (Shivange et al., 2019).

We conducted cDNA transfection experiments on iSketSnFR1_PM, iSKetSnFR2_PM, iSketSnFR1_ER, and iSketSnFR2_ER in Neuro2a cells. Neuro2a cells were purchased from ATCC $^{1}$ and cultured according to ATCC protocols. For chemical transfection, we utilized either Lipofectamine 2000 or Lipofectamine 3000, following the manufacturer's recommended protocol. Cells were incubated in the transfection medium for 24 $\mathrm{h}$ and then in growth media for $\sim 24 \mathrm{~h}$ before imaging.

\section{Expression in Dopaminergic Neurons Differentiated From Human Induced Pluripotent Stem Cells (iPSCs)}

Fujifilm CDI ${ }^{2}$ (formerly named Cellular Dynamics International, Madison WI, USA), furnished iCell DopaNeurons. These are human dopaminergic neurons differentiated from induced pluripotent stem cells (iPSCs). The supplier has measured that $89 \%$ of the cells are positive for tyrosine hydroxylase by fluorescence-activated cell sorting. The iCell DopaNeurons were maintained in 95\% BrainPhys Neuronal medium (STEMCELL Technologies ${ }^{3}$ ), 2\% iCell Neural Supplement B (CDI), 1\% iCell Nervous System Supplement (CDI), $0.1 \%$ of $1 \mathrm{mg} / \mathrm{ml}$ laminin (Sigma), 1\% N-2 Supplement $100 \times$ (Thermo Fisher Scientific, Waltham, MA, USA) and supplemented with penicillin and streptomycin. iCell DopaNeurons were maintained on dishes for 17-24 days before imaging. Glass bottoms of the 35-mm imaging dishes (MatTek ${ }^{4}$ ) were coated with $\sim 0.07 \%$ poly(ethyleneimine) solution and incubated at $37^{\circ} \mathrm{C}$ for $1 \mathrm{~h}$. Dishes were rinsed with PBS, then rinsed with water and air-dried overnight. Glass bottoms were then coated with $80 \mu \mathrm{g} / \mathrm{ml}$ laminin solution for 30 min at $37^{\circ} \mathrm{C}$ before cells were plated. We confirmed that $\geq 40 \%$ of the cells stained for $\mathrm{TH}$ by immunocytochemistry using a previously described assay (Srinivasan et al., 2016).

Cultured iCell DopaNeurons were transfected after either 13 or 21 days in culture using the Viafect kit (Promega, Cat. $\# \mathrm{E} 4981)$ at 4:1 transfection reagent $(\mu \mathrm{l})$ : DNA $(\mu \mathrm{g})$ ratio. The transfection mixture was prepared in $100 \mu \mathrm{l}$ OptiMEM (Thermo Fisher Scientific, Waltham, MA, USA) containing $4 \mu \mathrm{l}$ of Viafect transfection reagent and $1 \mu \mathrm{g}$ of cDNA. The mixture was incubated for $10-15 \mathrm{~min}$, then added directly to fresh maintenance medium in the culture dish. Transfection medium was removed after $24 \mathrm{~h}$ and cells incubated for $48-72 \mathrm{~h}$ further before imaging.

\footnotetext{
${ }^{1}$ www.attc.org

${ }^{2}$ fujifilmcdi.com

3 www.stemcell.com

${ }^{4}$ www.mattek.com
}

\section{Time-Resolved Fluorescence Measurements in Live Mammalian Cells}

We find that signals with the iSKetSnFR constructs have brightness similar to those of the previous iNicSnFR cpGFPbased biosensors for nicotine (Shivange et al., 2019), but the dynamic range is somewhat lower for the iKetSnFRs. Datasets were taken on an Olympus IX-81 microscope, in widefield epifluorescence mode. Images were acquired at 3-4 frames/s with a back-illuminated EMCCD camera (iXon DU-897, Andor Technology USA, South Windsor, CT, USA; Pantoja et al., 2009), controlled by Andor IQ2 or IQ3 software. Fluorescence measurements at $\lambda_{\mathrm{ex}}=470 \mathrm{~nm}$ have been described (Shivange et al., 2019). We also installed a second LED for excitation at $405 \mathrm{~nm}$. The epifluorescence cube was previously described (Srinivasan et al., 2011). The $40 \times$ lens proved most convenient for imaging several adjacent cells and was relatively insensitive to modest drift of the focus. PM-directed constructs were measured with a region of interest (ROI) that included only the cell periphery.

Solutions were delivered from elevated reservoirs by gravity flow, through solenoid valves (Automate Scientific, Berkeley, CA, USA), then through tubing fed into a manifold, at a rate of 1-2 $\mathrm{ml} / \mathrm{min}$. Experiments were performed with HBSS buffer, except that iPSC-derived neurons were studied in PBS plus D-glucose (5.56 mM), $\mathrm{MgCl}_{2}(0.49 \mathrm{mM}), \mathrm{MgSO}_{4}(0.4$ $\mathrm{mM}), \mathrm{KCl}(5.33 \mathrm{mM})$, and $\mathrm{CaCl}_{2}(1.26 \mathrm{mM})$. Other details have been described (Shivange et al., 2019). As usual in fluorescence imaging experiments, we excluded data from the brightest cells, because these may have fluorescent impurities or aggregates that produce a rapidly bleaching baseline. Data analysis procedures included subtraction of blank (extracellular) areas and corrections for baseline drifts.

\section{Confocal Fluorescence Imaging}

For laser scanning confocal fluorescence imaging, Neuro2a cells were transfected with iSKetSnFR1_PM, iSKetSnFR2_PM, iSketSnFR1_ER, or iSketSnFR2_ER $(0.5 \mu \mathrm{g})$ with the aid of either Lipofectamine 2000 or Lipofectamine 3000, using the manufacturer's recommended protocol. The images were acquired with a Zeiss LSM 710 laser-scanning confocal microscope, equipped with a $63 \times$ NA 1.4 objective lens. HBSS was used to wash and replace the growth medium in the dishes before imaging. GFP illumination was at $488 \mathrm{~nm}$, observed through a $495-550 \mathrm{~nm}$ band-pass filter.

\section{The S-Slope}

We introduce a convenient metric to summarize progress in evolving increasingly sensitive fluorescent biosensors for drugs. The metric, the S-slope, is especially appropriate for low drug concentrations because it corresponds to the relationship between [drug] and $\Delta \mathrm{F}$ at the beginning of the dose-response relation. We define the S-slope for use with intensity-based drug biosensors:

$$
\text { S-slope }=\Delta\left(\frac{F}{F_{0}}\right) /(\Delta[d r u g]) .
$$

We state the S-slope in units of $\mu \mathrm{M}^{-1}$. 
This article uses the S-slope for measurements on S-ketamine biosensors in bacterial lysates, with purified proteins, and expressed in cells. For measurements with bacterial lysates and with purified proteins, it is usually possible to construct a complete dose-response relation with a Hill coefficient close to 1 . In this case, we calculated (as in Figure 2A below),

$$
\text { S-slope }=\frac{\Delta F_{\max }}{F_{0}} / E C_{50}
$$

\section{Reagents}

All solvents purchased were of analytical grade and used without further purification. S-ketamine $\mathrm{HCl}$ was purchased from SigmaAldrich (St. Louis, MO, USA; Cat. \#K1884, CAS \#33643-47-9. We purchased R-ketamine $\mathrm{HCl}$ from Cayman Chemicals (Ann Arbor, MI, USA; Cat. \#16519, CAS\#33795-24-3).

\section{Data Analysis}

Image movie files, spectral data, and dose-response data were analyzed further and presented with general-purpose software. These programs include ImageJ2 (Rueden et al., 2017), Excel (Microsoft), and Origin (OriginLab). All the sequencing analyses used Benchling.

\section{RESULTS}

\section{Development of iSKetSnFR1 and iKetSnFR2}

We tested S-ketamine and R-ketamine (Figure 1) against iNicSnFR1, iNicSnFR2, and iNicSnFR3a, as well as against 12 other biosensors in the series that led to the iNicSnFRs (Shivange et al., 2019). We found no detectable fluorescence increase activated by S-ketamine, at concentrations $<100 \mu \mathrm{M}$.

For further insights, we computationally docked S-ketamine into the structure of iNicSnFR1 (PDB file 6EFR), and several computationally mutated variants (Supplementary Figure S1). In the highest-ranked results, the predicted distances between the $\mathrm{S}$-ketamine $\mathrm{N}$ atom and the aromatic groups are too great to form a cation $-\pi$ interaction of the type suggested by docking, structural, and mutational studies for the iNicSnFR series with nicotine, acetylcholine, and varenicline (Shivange et al., 2019).

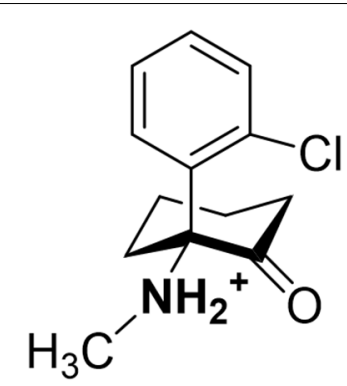

S-ketamine

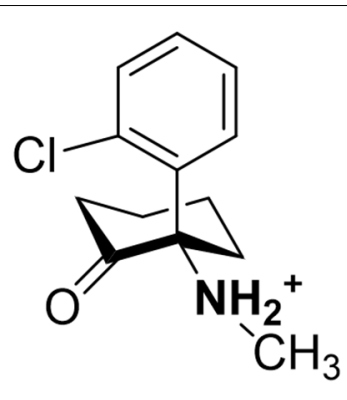

R-ketamine
These observations, while heuristic and not definitive, suggested that we mutate the aromatic residues.

When we applied SSM to the Tyr357 position, we found S-ketamine responses, but only for a Gly residue at position $357\left(\Delta \mathrm{F} / \mathrm{F}_{0} \sim 0.12\right.$ at $\left.1 \mu \mathrm{M}\right)$. While insufficiently sensitive for systematic measurements, this construct (AK1) provided an entry for further SSM experiments.

After we identified AK1, further rounds of SSM (retaining the Gly357 codon) led to improvements by mutations at and near the ligand site, including positions 10,436 , and 457 . The iSketSnFR1 construct has an S-slope of $0.32 \mu \mathrm{M}^{-1}$, nearly equal to that of nicotine for iNicSnFR3a and iNicSnFR3b (Shivange et al., 2019). Thus, in vitro, one expects a response to $1 \mu \mathrm{M}$ S-ketamine of $\Delta \mathrm{F} / \mathrm{F}_{0}=0.32$. The actual recorded data in cells were in this range (see below). The development series has culminated in iSketSnFR2, which has an S-slope of $1.87 \mu \mathrm{M}^{-1}$ (Figure 2).

We note the presence of the Phe436Trp mutation (referred to the original OpuBC periplasmic binding protein). One conformer of the Trp side chain can fit into the vacancy left by the absence of a side chain at Gly357. This combination may re-establish a cation- $\pi$ interaction with the nitrogen of ketamine; further structural analysis would test this hypothesis.

We also note the substantial increased sensitivity for the Met10 codon (from AK7 to iSketSnFR2). We have no explicit structural explanation for the effectiveness of this mutation.

\section{pH Dependence of iKetSnFRs}

Studies of the $\mathrm{pH}$ dependence on the GCaMP family provide a mechanistic background for other biosensors that use cpGFP. In the inactive conformation of cpGFP, the fluorophore has a pKa of 8-9, and a second at a higher, only approximately characterized $\mathrm{pH}$. At neutral $\mathrm{pH}$, the fluorophore is almost fully protonated, decreasing the absorption in the band centered at $\lambda_{\text {ex }} \sim 485 \mathrm{~nm}$ (Barnett et al., 2017). In the active form, the $\mathrm{pKa}$ is $\sim 7$, so that some of the fluorophore molecules are deprotonated. This allows absorption and fluorescence (Barnett et al., 2017). Possibly both the $\mathrm{pH}$ dependence of the biosensor and that of the ligand affect measurements with iSketSnFR1 and iSketSnFR2.

Therefore, in the $\mathrm{pH}$ range from 6 to 8.5, we determined the $\Delta \mathrm{F}$ dose-response relations of iSketSnFR1 and iSketSnFR2 using excitation at $\lambda_{\text {ex }}=485 \mathrm{~nm}$ (Figure 2C). The greatest S-slope occurs at $\mathrm{pH} 7.0-8.5$, resulting from maximal $\Delta \mathrm{F}_{\max } / \mathrm{F}_{0}$ at $\mathrm{pH}$ 6.5-7 and an $\mathrm{EC}_{50}$ that decreases monotonically with $\mathrm{pH}$. Both those trends resemble results with the iNicSnFR family (Shivange et al., 2019). For measurements at $\lambda_{\mathrm{ex}}=400 \mathrm{~nm}$, see Figure 7 below and Supplementary Figure S2.

The permanently charged nicotine analog, N'-methylnicotinium, previously provided additional insights for the iNicSnFR family (Shivange et al., 2019). The analogous S-ketamine derivative, N,N-dimethyl-S-ketamine, did not produce robust activation of the iSketSnFR constructs, vitiating experiments to study the possible role of charge at the nitrogen atom. This is consistent with but does not prove a reduced role for cation- $\pi$ interactions between S-ketamine and the biosensor. Regardless of the underlying

FIGURE 1 | Structures of S-ketamine and R-ketamine. 


\section{A}
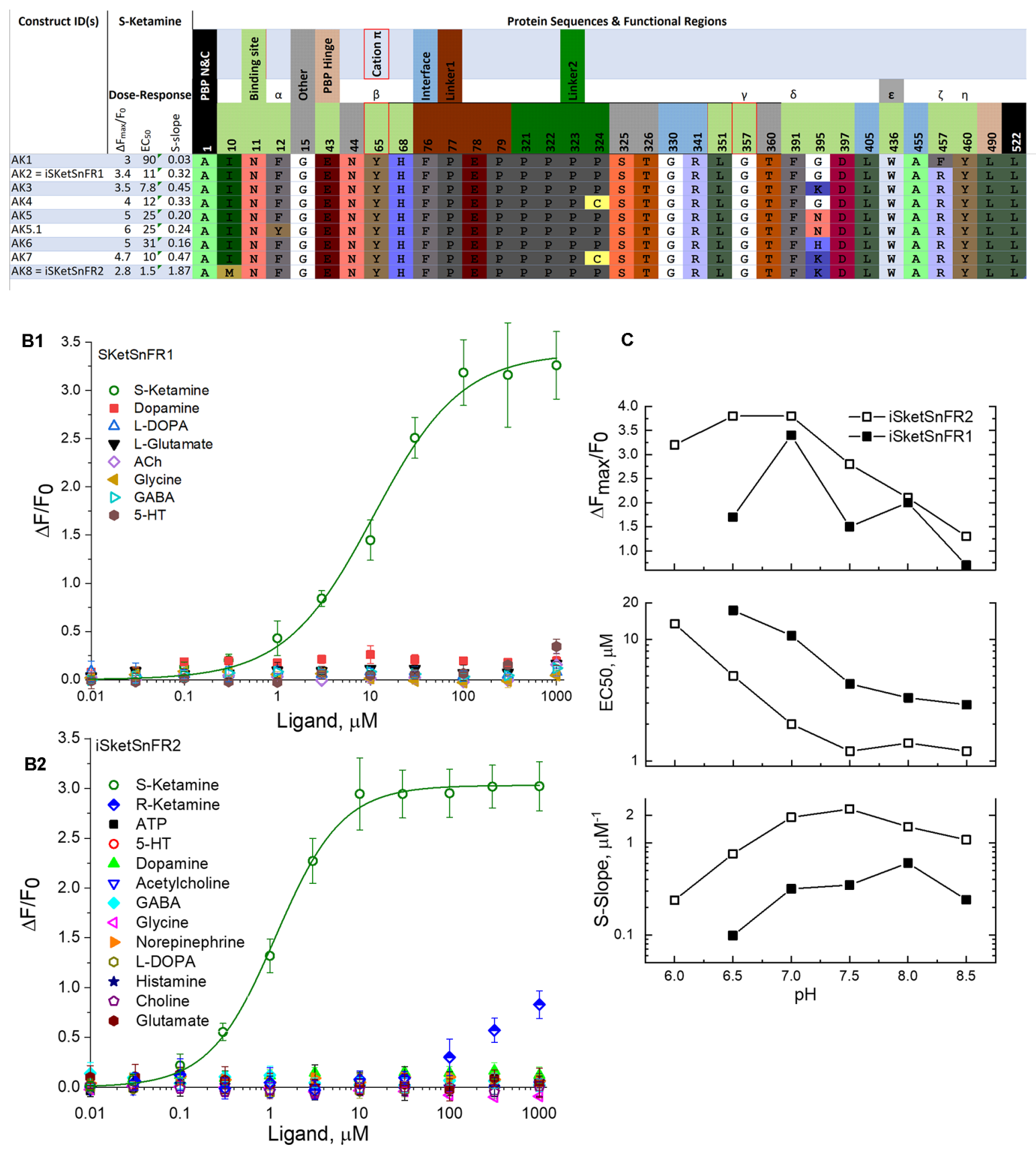

C
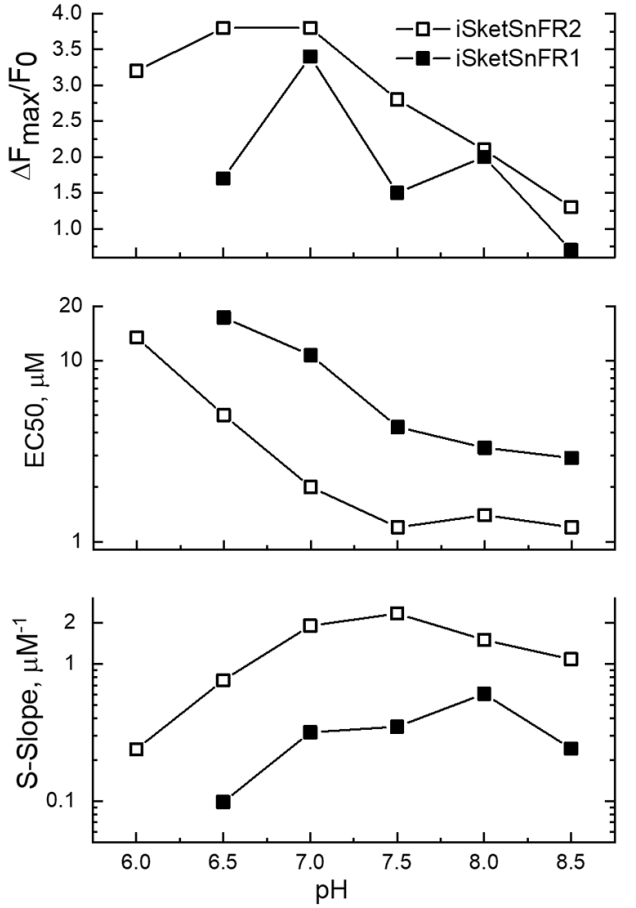

FIGURE 2 | Sequences, dose-response relations, and pH dependence of iSketSnFR1, iSketSnFR2 and related proteins. (A) Sequences of eight iKetSnFRs studied. The names iSketSnFR1 and iSketSnFR2 correspond to AK2 and AK8. Functional regions of the biosensor protein are shown as stippled cells above the sequences. Regions highlighted include those surrounding the ligand ("binding site"), the interface between the PBP and the cpGFP moiety, the two linker sequences leading from the PBP to the cpGFP, and vice versa, and the PBP hinge. The N- and C-terminal amino acids are also shown. The numbering corresponds to PDB entry 6EFR (Shivange et al., 2019). The cpGFP moiety, not shown, runs from codon 80 to 320. Greek letters denote aromatic groups that were candidates for cation- $\pi$ interactions with the $\mathrm{N}$-atom of the ligand (Shivange et al., 2019), and red borders denote those with the strongest evidence. The residues shown were mutated in this study or in a previous study that generated iNicSnFR biosensors. The background colors for amino acids, similar to those in JMOL, have no chemical meaning but are chosen to provide a wide, distinguishing range of colors. There is no correspondence between the background color of the stippled entries and the background color for the codons. (B1) Dose-response relations for purified iSketSnFR1, studied for various ligands at pH 7.0, 3x phosphate-buffered saline (PBS; Shivange et al., 2019). The data for $S$-ketamine have been fitted to the Hill equation, $\Delta F_{\max } / F_{0}=3.4 \pm 0.1$ and $E_{50} 10.7 \pm 1.5 \mu M, H i l l$ coefficient $\left(n_{H}\right)=$ $0.91 \pm 0.09$. 


\section{FIGURE 2 | Continued}

The other seven ligands tested yielded responses that were too small for systematic study. (B2) Dose-response relations for purified iSketSnFR2, studied for various ligands at pH 7.0, 3× PBS (Shivange et al., 2019). The data for S-ketamine have been fitted to the Hill equation, $\Delta F_{\max } / F_{0}=3.0 \pm$ 0.3 and $\mathrm{EC}_{50} 1.16 \pm 0.6 \mu \mathrm{M}$, Hill coefficient $\left(\mathrm{n}_{H}\right)=1.18 \pm 0.07$. The other 12 ligands tested yielded responses that were too small for systematic study. (C) Dose-response parameters at varying pH values between 6.0 and 8.5, for S-ketamine at purified iSketSnFR1 and iSketSnFR2. Data are included for curve fits that gave $\mathrm{n}_{H}$ values between 0.75 and 1.2 and $\mathrm{EC}_{50}$ values $<$ $50 \mu \mathrm{M}$. The plots show that iSketSnFR2 has the most favorable S-slope at all $\mathrm{pH}$ values studied, because of both its lower $\mathrm{EC}_{50}$ and its higher $\Delta \mathrm{F}_{\max } / \mathrm{F}_{0}$

mechanism, the data suggest that the $\mathrm{pH}$ dependence of iSketSnFR1 and of iSketSnFR2 is dominated by that of the cpGFP moiety rather than by that of the weakly basic ligand, S-ketamine.

\section{The _PM and_ER Constructs Reach the Intended Organelles}

We examined the subcellular localization of the iSKetSnFR2_PM and iSketSnFR2_ER constructs, using confocal microscopy (Figure 3). The iSKetSnFR2_PM construct shows the expected localization at the cell periphery (Figure 3A). The iSketSnFR2_ER construct shows the expected intracellular localization, including the nuclear lamina (Figure 3B). Neuro2a cells are not ideal for distinguishing among organelles, and it is possible that some fluorescence arises from localization in both the ER and Golgi. For both the iSKetSnFR2_PM and iSketSnFR2_ER constructs, we noted clear increases in fluorescence when we added $1.5 \mu \mathrm{M}$ S-ketamine. We described this increase systematically in the specialized, timeresolved, albeit lower-resolution imaging experiments presented below. Similar images were obtained for iSketSnFR1_PM and iSketSnFR1_ER.

\section{Time-Resolved Responses to S-Ketamine in Live Cells}

The S-slope of iSketSnFR1 for S-ketamine roughly equals that of nicotine for iNicSnFR3a and iNicSnFR3b. As expected from this similarity, iSketSnFR1 provided meaningful time-resolved doseresponse relations for S-ketamine, at concentrations $>1 \mu \mathrm{M}$ (Figure 4). Transfected Neuro2a cells readily displayed $\Delta \mathrm{F}$ within a few seconds after the external solution was switched to one containing S-ketamine; and the fluorescence decreased to baseline within a few seconds after the external solution was switched to a ketamine-free solution. The half-maximal concentration of S-ketamine is $\sim 10 \mu \mathrm{M}$, near the concentration measured with purified protein.

The rapid antidepressant effects of S-ketamine occur after peak blood plasma concentrations of $0.2-1 \mu \mathrm{M}$, and free brain concentration of S-ketamine may be similar (Lester et al., 2012; Janssen Research and Development, 2019). Although the Hill coefficient near unity implies that measurement at [S-ketamine] $>1 \mu \mathrm{M}$ can be linearly extrapolated to provide meaningful insights for lower [S-ketamine], we sought direct measurements at the pharmacologically relevant [S-ketamine]. Our most powerful and sensitive tool for such a study is

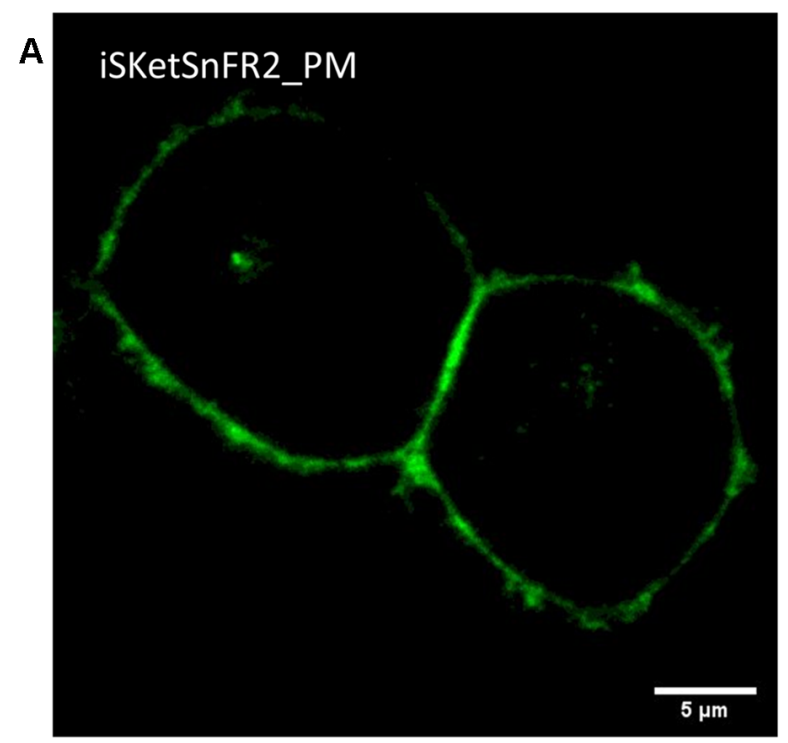

\section{B iSKetSnFR2_ER}

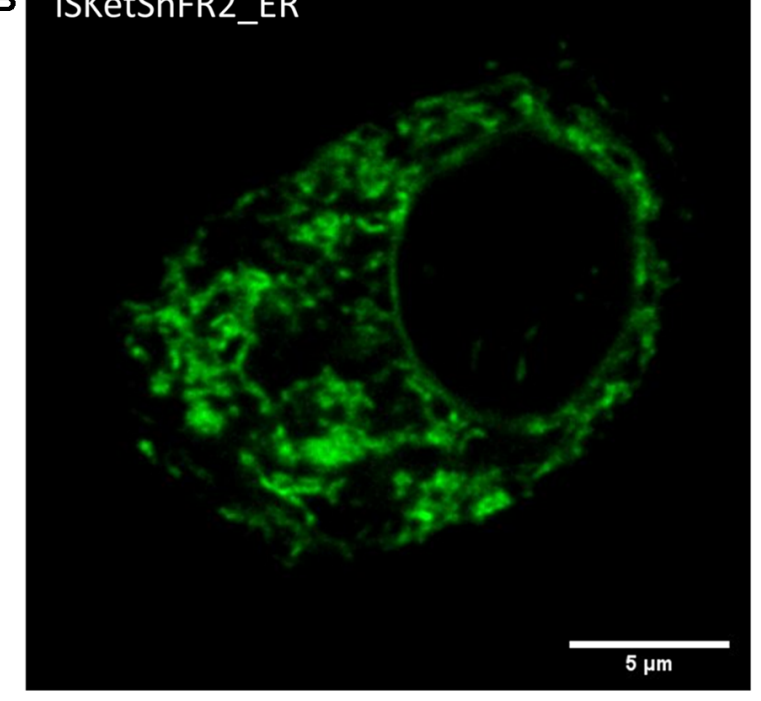

FIGURE 3 | Confocal imaging. (A) Typical plasma membrane (PM) fluorescence pattern of a representative Neuro2a cell transfected with iSketSnFR2_PM. Panel (B) Typical intracellular fluorescence pattern of a representative Neuro2a cell transfected with iSketSnFR2_ER.

iSketSnFR2, with its S-slope of $1.9 \mu \mathrm{M}^{-1}$ at purified protein. Transfected Neuro2a cells readily displayed measurable $\Delta \mathrm{F}$ within a few seconds after the external solution was switched to an S-ketamine solution; and the fluorescence decreased to baseline within a few seconds after the external solution was switched to a ketamine-free solution (Figure 5). We plotted data for [S-ketamine] $\leq 1 \mu \mathrm{M}$, which is less than the $\mathrm{EC}_{50}$ measured with purified iSketSnFR2 protein. This ensures that our measurements remain on the linear part of a conventional dose-response relation. Summarizing our experiments on cells expressing targeted iSketSnFR2 constructs for [S-ketamine] $<1 \mu \mathrm{M}$, iSketSnFR2_PM displayed an Sslope $=0.42 \pm 0.14 \mu \mathrm{M}^{-1}$ (mean $\pm \mathrm{SD}, 25$ total cells from 


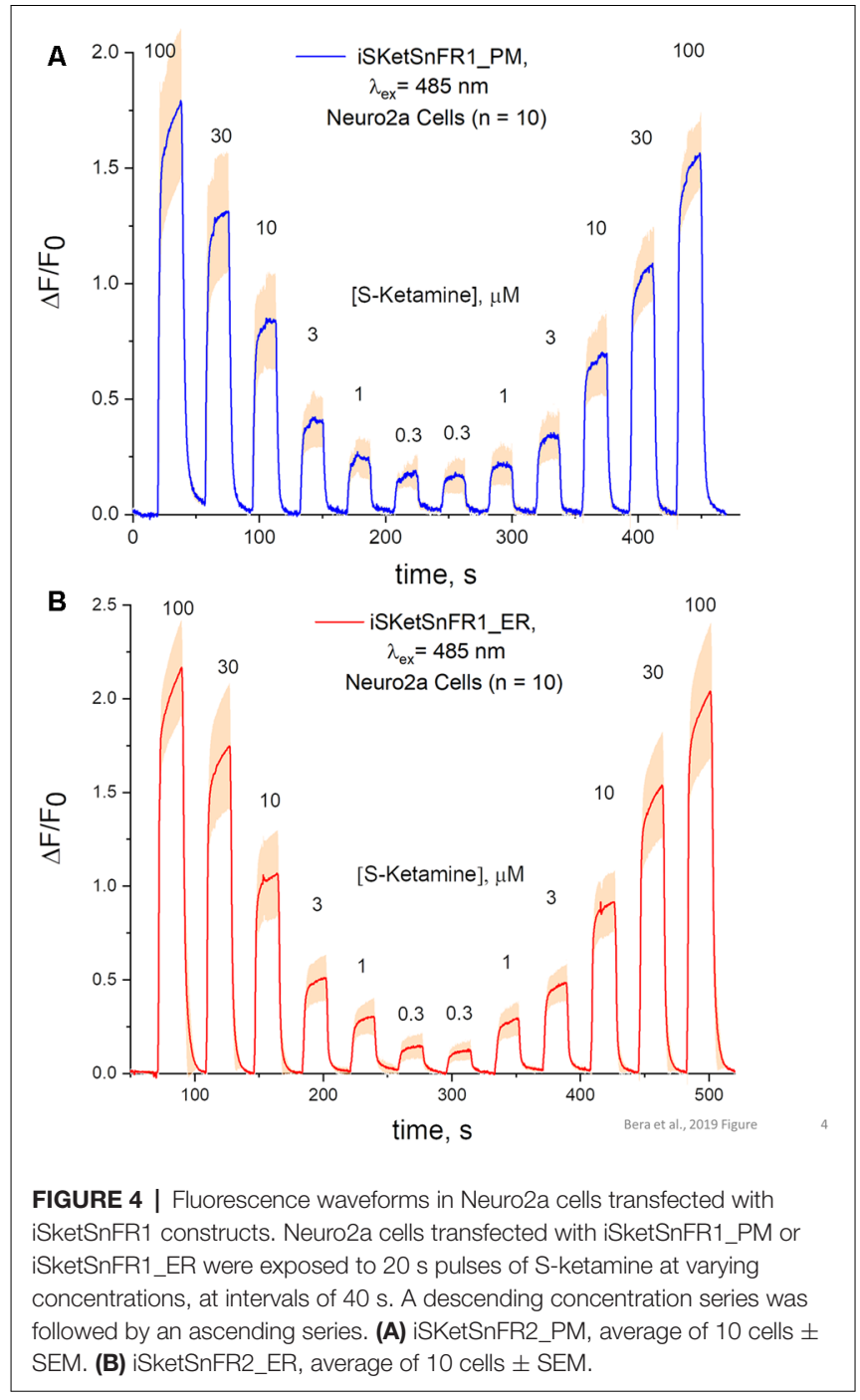

two independent transfections) and iSketSnFR_ER displayed an S-slope $=0.29 \pm 0.04 \mu \mathrm{M}^{-1}$ (mean $\pm \mathrm{SD}, 25$ total cells from two independent transfections). These S-slopes do not differ significantly.

\section{Time-Resolved Responses to S-Ketamine in iPSC-Derived Dopaminergic Neurons}

We also studied iPSCs differentiated to become dopaminergic neurons (Shivange et al., 2019) and transfected with either iSketSnFR1_PM or iSketSnFR1_ER. In these cells, responses to S-ketamine appeared and decreased within just a few seconds after jumps in the extracellular S-ketamine concentration (Figure 6), resembling the results in Neuro2a cells. Responses increased linearly with concentration when we applied Sketamine at concentrations $<$ the $\mathrm{EC}_{50}$ (Figure 6). The experimentally determined S-slope for iSketSnFR1_PM was $0.1 \mu^{-1}$, or $\sim 4$-fold lower than the value measured for iSKetSnFR2_PM in Neuro2a cells. Importantly, iSketSnFR1_ER constructs in iPSCs displayed an S-slope only slightly greater than that of the iSketSnFR1_PM construct.

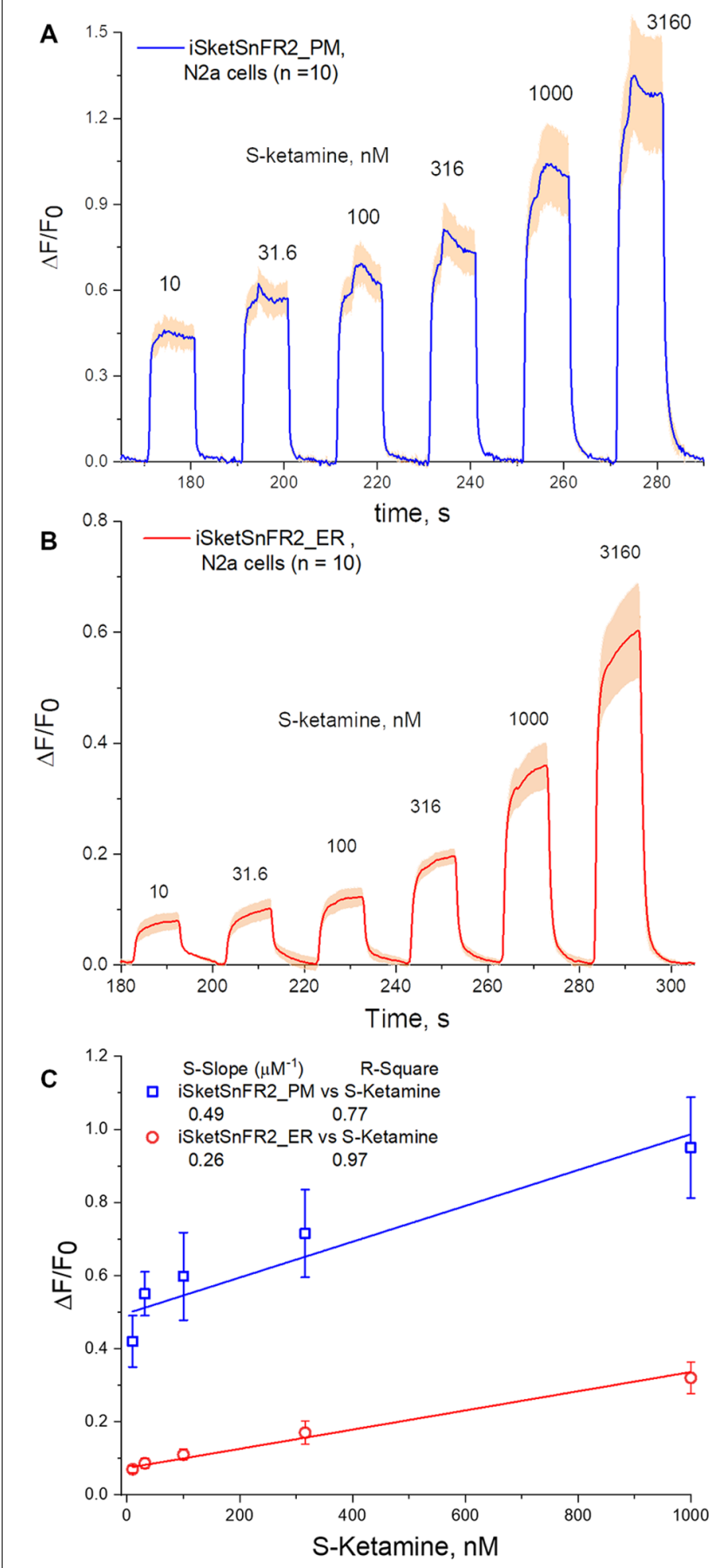

FIGURE 5 | Fluorescence waveforms in Neuro2a cells transfected with iSketSnFR2 constructs and exposed to sub- $\mu$ M S-ketamine. Transfected Neuro2a Cells were exposed to an ascending concentration series of $10 \mathrm{~s}$ pulses of S-ketamine at intervals of 20 s. (A) iSKetSnFR2_PM, average of 10 cells \pm SEM. (B) iSketSnFR2_ER, average of 10 cells \pm SEM. (C) S-slope calculations from linear fits to the $\Delta F / F_{0}$ data for the final $5 \mathrm{~s}$ of each application.

S-slopes measured for PM and ER constructs in cells are several fold lower than for purified iSketSnFR proteins, as also observed for iNicSnFR constructs (Shivange et al., 

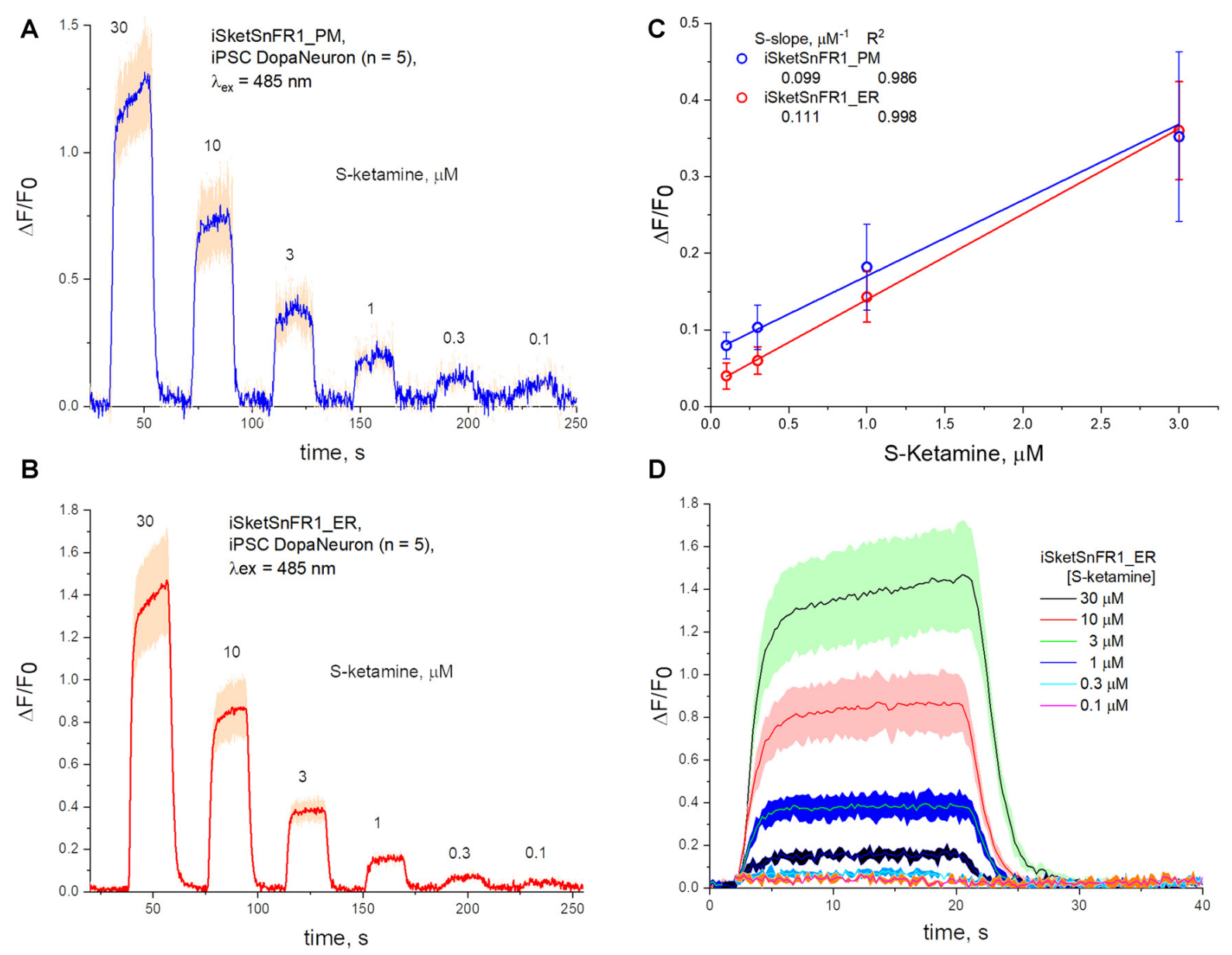

FIGURE 6 | Fluorescence waveforms in induced pluripotent stem cells (iPSCs) transfected with iKetSnFR1 constructs. Dopaminergic neurons differentiated from iPSCs were transfected with (A) iSketSnFR1_PM or (B) iSketSnFR1_ER. S-ketamine was perfused at varying concentrations for $20 \mathrm{~s}$, at $38 \mathrm{~s}$ intervals. Average of five cells, \pm SEM. (C) S-slope calculations. (D) Averaged waveforms for (B) on an expanded time axis.

2019). Furthermore, S-slopes measured in cells for iSketSnFR2 constructs are $\sim 2$ - to 4 -fold higher than for iSketSnFR1, rather than 5.8-fold higher as measured for the purified biosensor proteins. Both these differences presumably arise because cellular experiments have appreciable contributions to $\mathrm{F}_{0}$ from other fluorescent molecules. Further experiments with various optical arrangements and with various cell types are required. The major conclusion is that, for two cell types and for two iSketSnFR biosensor proteins, the ER S-ketamine concentration follows the extracellular concentration, within a few seconds and within 2-fold.

\section{Excitation at $400 \mathrm{~nm}$ vs. $485 \mathrm{~nm}$}

Previous studies indicate that cpGFP-based sensors can also provide information when excited at $400 \mathrm{~nm}$ (Barnett et al., 2017). In tests at $\mathrm{pH} 7$, we found that the $\mathrm{EC}_{50}$ is not markedly different at 400 and $485 \mathrm{~nm}$, as though measurements are detecting a common binding and conformational change event (Figure 7A). The S-slope at $\mathrm{pH} 7$ is -0.23 , some 7 -fold lower than at $485 \mathrm{~nm}$ (and opposite in sign). With iSketSnFR1_ER, we tested whether one can monitor S-ketamine entry into the $\mathrm{ER}$ at $\lambda_{\mathrm{ex}}=400 \mathrm{~nm}$, even though the lower S-slope produces a lower signal-to-noise ratio. As shown in Figure $\mathbf{7 B}$, this is possible, but only at [S-ketamine] in the higher range of the dose-response relation.

In measurements on purified iSketSnFR2, we compared the $\mathrm{pH}$ sensitivity for measurements at $\lambda_{\mathrm{ex}}=400 \mathrm{~nm}$ and at $\lambda_{\mathrm{ex}}$ $=485 \mathrm{~nm}$. We confirmed that the $\mathrm{EC}_{50}$ for S-ketamine does remain approximately equal when tested at $\lambda_{\text {ex }}=400 \mathrm{~nm}$ vs. $485 \mathrm{~nm}$, increasing at lower $\mathrm{pH}$ (compare Figure 2C vs. Supplementary Figure S2). A similar trend was previously noted for iNicSnFR3a. This trend is opposite to the expectation for a response limited only by the fraction of protonated ligand in the solution (Shivange et al., 2019). Therefore, we restate the previous suggestion that the $\mathrm{pH}$ dependence of S-ketamine measurements with iSketSnFR sensors is dominated by the $\mathrm{pH}$ sensitivity of the biosensor protein, not of the S-ketamine ligand. Because of this sensitivity, the [S-slope] for $\lambda_{\mathrm{ex}}=400 \mathrm{~nm}$ becomes quite small at $\mathrm{pH}<7$, never exceeding 0.3 even for iSketSnFR2 (Supplementary Figure S2). 

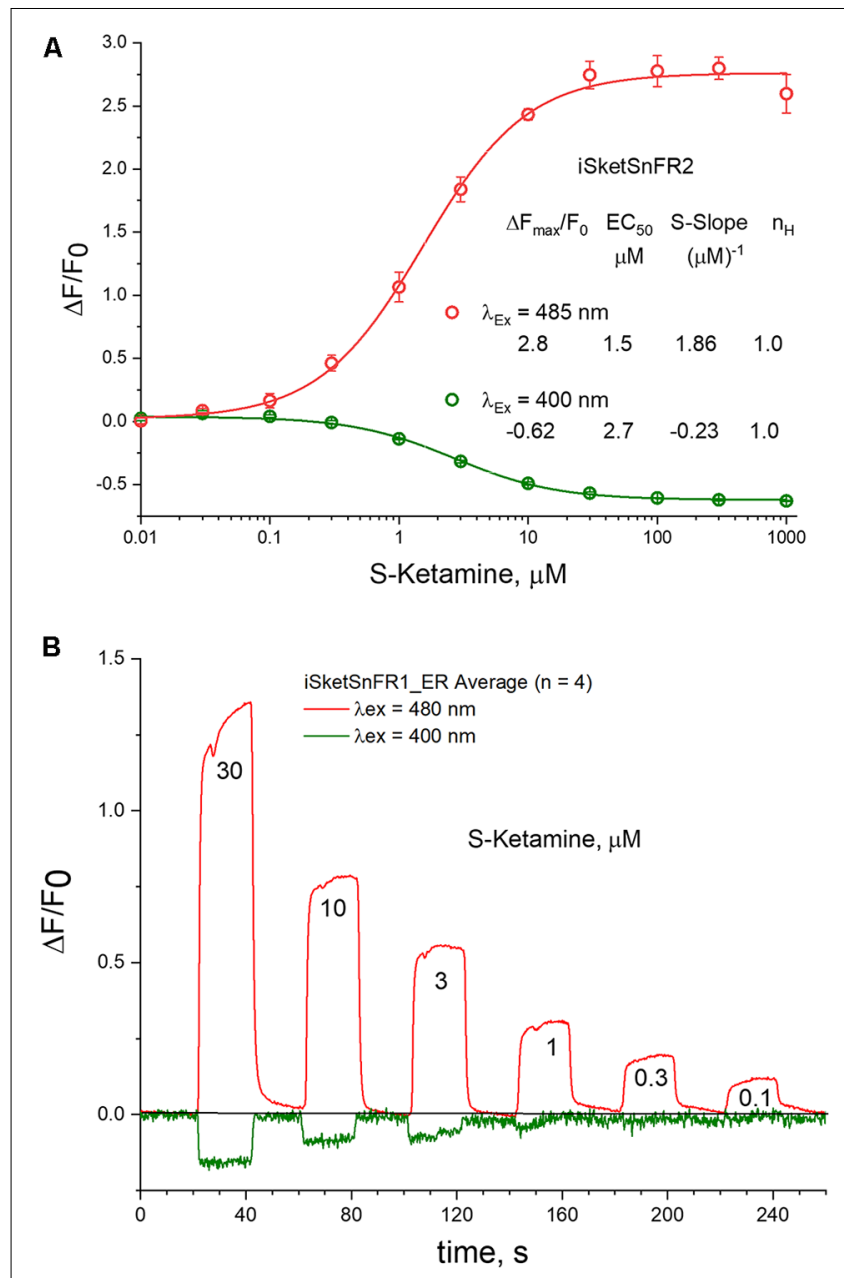

FIGURE 7 | 485 vs. 400 nM excitation. (A) Dose-response relations in solution for iSketSnFR2, excited at 400 vs. $485 \mathrm{~nm}$. (B) Live-cell imaging for iSketSnFR1, with either $485 \mathrm{~nm}$ or $400 \mathrm{~nm}$ excitation. Pulses of varying S-ketamine concentration lasting $20 \mathrm{~s}$, at $40 \mathrm{~s}$ intervals.

\section{DISCUSSION}

\section{S-Ketamine in Organelles}

As pointed out in the "Introduction" section, in the absence of well-established information about a drug's target, one needs to know which compartments a drug enters, how quickly, and at what concentrations. The present study establishes that Sketamine enters the ER within a few seconds after appearing near cells, then leaves within a few seconds after S-ketamine is removed from the extracellular space. The S-ketamine concentration in the ER is less than 2-fold different from that in the extracellular solution. These conclusions arise from data on two biosensor constructs (iSketSnFR1, iSketSnFR2) and on two cell types (Neuro2a and human dopaminergic neurons differentiated from iPSCs).

A previous report shows that ketamine enters cells (Emnett et al., 2016). The pharmacological role of entry into organelles may differ between nicotine and S-ketamine; the former was studied in a previous article on ER permeation (Shivange et al.,
2019). For nicotine, the ER is a major compartment relevant for pharmacological chaperoning and upregulation-the early stages of nicotine dependence (Henderson and Lester, 2015). For S-ketamine, if target engagement occurs in an organelle rather than on the PM, that organelle is still unknown. The sigma-1 receptor, a binding site for both R-ketamine and S-ketamine, occurs in the ER (Su, 2019).

Other organelles should also be considered as possible compartments for target engagement by S-ketamine. In 1974, it was first pointed out that weak bases accumulate, perhaps by factors of 100, in lysosomes and other acidic compartments (de Duve et al., 1974). In one suggestion, the relevant compartment(s) for S-ketamine are acidic vesicles (Lester et al., 2015; Stenovec et al., 2019). Uncertainties about the relevant acidic vesicles imply that the relevant $\mathrm{pH}$ is between 4.5 (lysosomes) and 5.5 (synaptic vesicles). Further uncertainties about ketamine permeability in the charged state allow for a wide range of intraluminal [S-ketamine] (Trapp et al., 2008). Therefore, it will be important to study intraluminal S-ketamine concentration directly.

The pharmacokinetic literature points out that lysosomes ( $\mathrm{pH} \sim 4.5$ ), representing just $\sim 1 \%$ of a cell's volume, would accumulate as much weakly basic drug as the entire cytoplasm (Smith et al., 2012). Antipsychotic drugs, which are also weak bases, accumulate in synaptic vesicles $(\mathrm{pH} \sim 5.5)$, and their release by pre-synaptic action potentials has both pre- and postsynaptic consequences (Trapp et al., 2008; Tischbirek et al., 2012; Tucker et al., 2015; Walters and Levitan, 2019). The present data provide the foundation for modifications of iSKetSnFR1 and iSKetSnFR2 that also function in acidic vesicles.

\section{Other Candidate Ketamine Analogs and Metabolites}

Candidate rapidly acting antidepressants include R-ketamine, as well as metabolites such as (2R, 6R)-hydroxynorketamine (HNK) and (2S, 6S)-HNK. Scopolamine also has rapid antidepressant actions (Wohleb et al., 2016). Biosensors tested in our experiments do respond, though quite weakly, to several of these compounds (Supplementary Figure S3). In previous experiments, the iNicSnFR series was "evolved" from initial biosensors characterized by an S-slope of $\sim 10^{-5}$ (Shivange et al., 2019). The strategy we describe could conceivably be extended to these ligands.

\section{Technical Considerations for Drug Biosensors}

We comment on developing "iDrugSnFRs," biosensors for synthetic and endogenous drugs. To some extent, the considerations differ from biosensors for endogenous neurotransmitters. For comparisons among intensity-based biosensors such as PBP-based or G protein-coupled receptor (GPCR)-based constructs, this article emphasizes the S-slope, a single metric that summarizes the beginning of the doseresponse relation. The $\mathrm{S}$-slope is simply $\Delta \mathrm{F}_{\max } / \mathrm{F}_{0}$ divided by the $\mathrm{EC}_{50}$. The S-slope has dimensions, $\mu \mathrm{M}^{-1}$. Use of the S-slope has the following advantages. 
(1) In our experience with isolated cells and in vivo systems, two factors usually render it desirable to follow the time course of relatively low drug concentrations. First, the pharmacological half-maximal dose is often less than the $\mathrm{EC}_{50}$ that characterizes the fluorescence. The S-slope describes sensitivity in the appropriate concentration range. Second, a full dose-response relation, in organelles of live cells, can be complicated if higher drug concentrations inhibit transporters, short-circuit proton gradients, or saturate buffers.

(2) An increased S-slope [pedantically, an increased (S-slope)] denotes an increased sensitivity. Interference by other drugs or neurotransmitters (again, at rather low concentrations) can be simply stated as the ratio of the S-slopes. This is an useful comparison if either $\mathrm{EC}_{50}$, or $\Delta \mathrm{F}_{\max } / \mathrm{F}_{0}$, or both vary among ligands. In the case of iSketSnFR1 and iSketSnFR2, all other ligands we measured have $\Delta \mathrm{F}$ responses so low that an $\mathrm{S}$-slope can be approximately determined only by extrapolation at higher concentrations (Supplementary Figure S3). R-ketamine, another ligand of interest which gives detectable responses at concentrations $>100 \mu \mathrm{M}$, has an S-slope at least 100-fold lower than S-ketamine at iSketSnFR2.

This article shows that S-slope comparisons between data on purified proteins have some predictive value. However, the S-slopes in cells, between iSketSnFR1 and iSketSnFR2, differed by smaller factors than those measured with purified protein, presumably because in cells, endogenous fluorescent molecules increase the $\mathrm{F}_{0}$ values.

(3) Use of a single parameter allows one to estimate the lowest analyte concentration observable, especially if one has characterized the fluorescence measurements in one's imaging instruments. In isolated cells, which have favorable fluorescence properties, we find that our instruments allow $\Delta \mathrm{F} / \mathrm{F}_{0}$ values of 0.1 to be resolved readily. Therefore, an S-slope of $0.3,1,3$, or 10 (Shivange et al., 2019) allows measurements as low as $\sim 0.3 \mu \mathrm{M}$, $\sim 0.1 \mu \mathrm{M}, 10 \mathrm{nM}$, or $3 \mathrm{nM}$, respectively.

(4) Use of the S-slope is more general than the previous metric, $\Delta \mathrm{F} / \mathrm{F}_{0}$ at $1 \mu \mathrm{M}$ ligand (Shivange et al., 2019). As noted above, this generality allows ready extensions to experiments that use only sub-micromolar concentrations of drugs. The S-slope can also be applied to decreases in fluorescence, for instance at $400 \mathrm{~nm}$ excitation (Figure 7). Because fluorescence cannot become less than zero, $\Delta \mathrm{F} / \mathrm{F}_{0}$ can never become more negative than -1 . However, $\mathrm{EC}_{50}$ can become so small that $\mathrm{S}$-slope values become more negative than $-1 \mu \mathrm{M}^{-1}$.

Use of the S-slope does require simplifications that occur with both PBP-based and GPCR-based fluorescent biosensors. These simplifications may not occur with less direct sensors such as those that measure Ca fluxes (Ding et al., 2019) or gene activation (Bick et al., 2017). One simplification appropriate to both PBP-based and GPCR-based biosensors: the Hill slope is near unity, so that responses $<$ the $\mathrm{EC}_{50}$ remain linear with the [drug].

Straightforward choices based solely on the S-slope are possible because here, as in Shivange et al. (2019), the binding and conformational changes are rapid enough to eliminate concerns caused by the response of the sensor itself. However, very low $\mathrm{K}_{\mathrm{d}}$ would depart from this experience. In the simplest view, the equilibrium $\mathrm{EC}_{50}\left(\mathrm{~K}_{\mathrm{d}}\right)$ is a ratio of two (possibly composite) kinetic steps, characterized phenomenologically as $\mathrm{K}_{\mathrm{d}}=\mathrm{k}_{\mathrm{off}} / \mathrm{k}_{\mathrm{on}}$. In our experience, $\mathrm{k}_{\mathrm{on}}$ values for OpuBC-based biosensors are $\sim 10^{7} / \mathrm{M} / \mathrm{s}$ (Shivange et al., 2019). Therefore, $\mathrm{K}_{\mathrm{d}}$ values $<10^{-7}$ $\mathrm{M}(100 \mathrm{nM})$ are accompanied by $\mathrm{k}_{\text {off }}<1 / \mathrm{s}$. Such values would produce a "lag" of $>1 \mathrm{~s}$ between the drug concentration and the fluorescence response.

An important final assumption is that in vitro and in vivo measurements occur at the same $\mathrm{pH}$. The S-slope does vary with $\mathrm{pH}$, because both its numerator and denominator vary with $\mathrm{pH}$ (Figure 2C, Supplementary Figure S2; Barnett et al., 2017; Shivange et al., 2019). We would like to extend the iDrugSnFR measurements to acidic organelles. With PBPGFP-based iDrugSnFRs, this is not yet possible: the S-slope approaches zero.

\section{Prospects for Developing Improved Rapidly Acting Antidepressants}

Knowing that S-ketamine enters organelles will not in itself develop a new $\sim 24 \mathrm{~h}$ antidepressant drug. Nonetheless, such data can help test whether novel mechanisms, such as action on intra-organellar targets and subcellular pharmacokinetics, must be considered in developing such drugs. Researchers may wish to test the subcellular pharmacokinetics, targets, compartment of target engagement, and downstream signaling events of other candidate drugs as rapidly acting antidepressants.

\section{DATA AVAILABILITY STATEMENT}

The datasets generated for this study are available on request to the corresponding author.

\section{AUTHOR CONTRIBUTIONS}

$\mathrm{KB}, \mathrm{AK}, \mathrm{AS}, \mathrm{PB}, \mathrm{IB}, \mathrm{TC}, \mathrm{AM}, \mathrm{SG}, \mathrm{CK}$ and JM: performed experiments. $\mathrm{KB}, \mathrm{AK}, \mathrm{AS}, \mathrm{AM}, \mathrm{AN}, \mathrm{JJ}, \mathrm{EL}, \mathrm{BC}, \mathrm{JM}$ and HL: analysis. BC, JM, LL and HL: research direction. EU and LT: constructs. AN, BC, KB, EL, LL and HL: manuscript preparation and revision. LL, KB and HL: funding.

\section{FUNDING}

This research was supported by grants from US National Institutes of Health (GM123582, MH120823, DA046122, NS090604, NS013522, MH107056), the California Institute for Regenerative Medicine (EDUC2-08398), the Brain and Behavior Research Foundation (NARSAD), the Della Martin Foundation, the Howard Hughes Medical Institute, the Caltech $\mathrm{CI}^{2}$ program, Caltech SURF donors David and Karen Rossum, and the Mistletoe Foundation.

\section{ACKNOWLEDGMENTS}

Jacob P. Keller: advice on $\mathrm{pH}$ and tubing. Laura Luebbert: help with experiments. Luke L. Lavis: synthesis of $\mathrm{N}, \mathrm{N}$ dimethyl-S-ketamine. Michael Maher: advice on ketamine. 
Anindya Bhattacharya: advice on ketamine. Daniel Wagenaar: construction of LED light sources. Lauren M. Barnett: advice on photochemistry. Eric R. Schreiter: biosensors. Jonathan Wang: technical help. Margaret Jefferies and Purnima Deshpande: excellent lab management at Janelia and Caltech.

\section{REFERENCES}

Adaikkan, C., Taha, E., Barrera, I., David, O., and Rosenblum, K. (2018). Calcium/calmodulin-dependent protein kinase II and eukaryotic elongation factor 2 kinase pathways mediate the antidepressant action of ketamine. Biol. Psychiatry 84, 65-75. doi: 10.1016/j.biopsych.2017.11.028

Autry, A. E., Adachi, M., Nosyreva, E., Na, E. S., Los, M. F., Cheng, P. F., et al. (2011). NMDA receptor blockade at rest triggers rapid behavioural antidepressant responses. Nature 475, 91-95. doi: 10.1038/nature10130

Barnett, L. M., Hughes, T. E., and Drobizhev, M. (2017). Deciphering the molecular mechanism responsible for GCaMP6m's $\mathrm{Ca}^{2+}$-dependent change in fluorescence. PLoS One 12:e170934. doi: 10.1371/journal.pone.0170934

Berman, R. M., Cappiello, A., Anand, A., Oren, D. A., Heninger, G. R., Charney, D. S., et al. (2000). Antidepressant effects of ketamine in depressed patients. Biol. Psychiatry 47, 351-354. doi: 10.1016/s0006-3223(99)00230-9

Beurel, E., Song, L., and Jope, R. S. (2011). Inhibition of glycogen synthase kinase-3 is necessary for the rapid antidepressant effect of ketamine in mice. Mol. Psychiatry 16, 1068-1070. doi: 10.1038/mp.2011.47

Bick, M. J., Greisen, P. J., Morey, K. J., Antunes, M. S., La, D., Sankaran, B., et al. (2017). Computational design of environmental sensors for the potent opioid fentanyl. Elife 6:e28909. doi: 10.7554/elife.28909

Blanpied, T. A., Boeckman, F. A., Aizenman, E., and Johnson, J. W. (1997). Trapping channel block of NMDA-activated responses by amantadine and memantine. J. Neurophysiol. 77, 309-323. doi: 10.1152/jn.1997.77.1.309

Buisson, B., and Bertrand, D. (1998). Open-channel blockers at the human $\alpha 4 \beta 2$ neuronal nicotinic acetylcholine receptor. Mol. Pharmacol. 53, 555-563. doi: $10.1124 / \mathrm{mol} .53 .3 .555$

Chen, X., Shu, S., and Bayliss, D. A. (2009). HCN1 channel subunits are a molecular substrate for hypnotic actions of ketamine. J. Neurosci. 29, 600-609. doi: 10.1523/JNEUROSCI.3481-08.2009

Coates, K. M., and Flood, P. (2001). Ketamine and its preservative, benzethonium chloride, both inhibit human recombinant $\alpha 7$ and $\alpha 4 \beta 2$ neuronal nicotinic acetylcholine receptors in Xenopus oocytes. Br. J. Pharmacol. 134, 871-879. doi: 10.1038/sj.bjp.0704315

de Duve, C., de Barsy, T., Poole, B., Trouet, A., Tulkens, P., and Van Hoof, F. (1974). Commentary. Lysosomotropic agents. Biochem. Pharmacol. 23, 2495-2531. doi: 10.1016/0006-2952(74)90174-9

Ding, K., Han, Y., Seid, T. W., Buser, C., Karigo, T., Zhang, S., et al. (2019). Imaging neuropeptide release at synapses with a genetically engineered reporter. Elife 8:e46421. doi: 10.7554/elife.46421

Emnett, C., Li, H., Jiang, X., Benz, A., Boggiano, J., Conyers, S., et al. (2016). A clickable analogue of ketamine retains NMDA receptor activity, psychoactivity, and accumulates in neurons. Sci. Rep. 6:38808. doi: 10.1038/srep38808

Emnett, C. M., Eisenman, L. N., Taylor, A. M., Izumi, Y., Zorumski, C. F., and Mennerick, S. (2013). Indistinguishable synaptic pharmacodynamics of the $\mathrm{N}$-methyl-D-aspartate receptor channel blockers memantine and ketamine. Mol. Pharmacol. 84, 935-947. doi: 10.1124/mol.113.089334

Frohlich, J., and Van Horn, J. D. (2014). Reviewing the ketamine model for schizophrenia. J. Psychopharmacol. 28, 287-302. doi: $10.1177 / 0269881113512909$

Gideons, E. S., Kavalali, E. T., and Monteggia, L. M. (2014). Mechanisms underlying differential effectiveness of memantine and ketamine in rapid antidepressant responses. Proc. Natl. Acad. Sci. U S A 111, 8649-8654. doi: 10.1073/pnas.1323920111

Hashimoto, K. (2019). Rapid-acting antidepressant ketamine, its metabolites and other candidates: a historical overview and future perspective. Psychiatry Clin. Neurosci. 73, 613-627. doi: 10.1111/pcn.12902

Henderson, B. J., and Lester, H. A. (2015). Inside-out neuropharmacology of nicotinic drugs. Neuropharmacol 96, 178-193. doi: 10.1016/j.neuropharm. 2015.01.022

\section{SUPPLEMENTARY MATERIAL}

The Supplementary Material for this article can be found online at: https://www.frontiersin.org/articles/10.3389/fncel. 2019.00499/full\#supplementary-material.

Janssen Research and Development. (2019). Esketamine Nasal Spray for Patients with Treatment-resistant Depression. Available online at: https://www.fda.gov/media/121377/download. Accessed August 15, 2019.

Johnson, J. W., Glasgow, N. G., and Povysheva, N. V. (2015). Recent insights into the mode of action of memantine and ketamine. Curr. Opin. Pharmacol. 20, 54-63. doi: 10.1016/j.coph.2014.11.006

Kapur, S., and Seeman, P. (2001). Ketamine has equal affinity for NMDA receptors and the high-affinity state of the dopamine D2 receptor. Biol. Psychiatry 49, 954-957. doi: 10.1016/s0006-3223(01)01110-6

Kapur, S., and Seeman, P. (2002). NMDA receptor antagonists ketamine and PCP have direct effects on the dopamine $\mathrm{D}_{2}$ and serotonin 5$\mathrm{HT}_{2}$ receptors-implications for models of schizophrenia. Mol. Psychiatry 7, 837-844. doi: 10.1038/sj.mp.4001093

Kille, S., Acevedo-Rocha, C. G., Parra, L. P., Zhang, Z. G., Opperman, D. J., Reetz, M. T., et al. (2013). Reducing codon redundancy and screening effort of combinatorial protein libraries created by saturation mutagenesis. ACS Synth. Biol. 2, 83-92. doi: 10.1021/sb300037w

Lee, R. H., Tseng, T. Y., Wu, C. Y., Chen, P. Y., Chen, M. F., Kuo, J. S., et al. (2012). Memantine inhibits $\alpha 3 \beta 2$-nAChRs-mediated nitrergic neurogenic vasodilation in porcine basilar arteries. PLoS One 7:e40326. doi: 10.1371/journal.pone. 0040326

Lepack, A. E., Fuchikami, M., Dwyer, J. M., Banasr, M., and Duman, R. S. (2014). BDNF release is required for the behavioral actions of ketamine. Int. J. Neuropsychopharmacol. 18:pyu033. doi: 10.1093/ijnp/pyu033

Lester, H. A., Lavis, L. D., and Dougherty, D. A. (2015). Ketamine inside neurons? Am. J. Psychiatry 172, 1064-1066. doi: 10.1176/appi.ajp.2015. 14121537

Lester, H. A., Miwa, J. M., and Srinivasan, R. (2012). Psychiatric drugs bind to classical targets within early exocytotic pathways: therapeutic effects. Biol. Psychiatry 72, 905-915. doi: 10.1016/j.biopsych.2012.05.020

Liu, R. J., Fuchikami, M., Dwyer, J. M., Lepack, A. E., Duman, R. S., and Aghajanian, G. K. (2013). GSK-3 inhibition potentiates the synaptogenic and antidepressant-like effects of subthreshold doses of ketamine. Neuropsychopharmacology 38, 2268-2277. doi: 10.1038/npp.2013.128

MacDonald, J. F., Bartlett, M. C., Mody, I., Pahapill, P., Reynolds, J. N., Salter, M. W., et al. (1991). Actions of ketamine, phencyclidine and MK-801 on NMDA receptor currents in cultured mouse hippocampal neurones. J. Physiol. 432, 483-508. doi: 10.1113/jphysiol.1991.sp018396

Marvin, J. S., Borghuis, B. G., Tian, L., Cichon, J., Harnett, M. T., Akerboom, J., et al. (2013). An optimized fluorescent probe for visualizing glutamate neurotransmission. Nat. Methods 10, 162-170. doi: 10.1038/ nmeth. 2333

Miller, O. H., Yang, L., Wang, C. C., Hargroder, E. A., Zhang, Y., Delpire, E., et al. (2014). GluN2B-containing NMDA receptors regulate depression-like behavior and are critical for the rapid antidepressant actions of ketamine. Elife 3:e03581. doi: 10.7554/eLife.03581

Moaddel, R., Abdrakhmanova, G., Kozak, J., Jozwiak, K., Toll, L., Jimenez, L., et al. (2013). Sub-anesthetic concentrations of (R,S)-ketamine metabolites inhibit acetylcholine-evoked currents in $\alpha 7$ nicotinic acetylcholine receptors. Eur. J. Pharmacol. 698, 228-234. doi: 10.1016/j.ejphar.2012.11.023

Pantoja, R., Rodriguez, E. A., Dibas, M. I., Dougherty, D. A., and Lester, H. A. (2009). Single-molecule imaging of a fluorescent unnatural amino acid incorporated into nicotinic receptors. Biophys. J. 96, 226-237. doi: 10.1016/j. bpj.2008.09.034

Preskorn, S. H., Baker, B., Kolluri, S., Menniti, F. S., Krams, M., and Landen, J. W. (2008). An innovative design to establish proof of concept of the antidepressant effects of the NR2B subunit selective N-methyl-D-aspartate antagonist, CP-101,606, in patients with treatment-refractory major depressive disorder. J. Clin. Psychopharmacol. 28, 631-637. doi: 10.1097/JCP.0b013e31818 a6cea 
Ren, Z., Pribiag, H., Jefferson, S. J., Shorey, M., Fuchs, T., Stellwagen, D., et al. (2016). Bidirectional homeostatic regulation of a depression-related brain state by $\gamma$-aminobutyric acidergic deficits and ketamine treatment. Biol. Psychiatry 80, 457-468. doi: 10.1016/j.biopsych.2016.02.009

Rueden, C. T., Schindelin, J., Hiner, M. C., DeZonia, B. E., Walter, A. E., Arena, E. T., et al. (2017). ImageJ2: ImageJ for the next generation of scientific image data. BMC Bioinformatics 18:529. doi: 10.1186/s12859-017-1934-z

Seeman, P., and Kapur, S. (2003). Anesthetics inhibit high-affinity states of dopamine D2 and other G-linked receptors. Synapse 50, 35-40. doi: 10.1002/syn.10221

Shivange, A. V., Borden, P. M., Muthusamy, A. K., Nichols, A. L., Bera, K., Bao, H., et al. (2019). Determining the pharmacokinetics of nicotinic drugs in the endoplasmic reticulum using biosensors. J. Gen. Physiol. 151, 738-757. doi: 10.1085/jgp.201812201

Smith, D., Allerton, C., Kalgutkar, A., van de Waterbeemd, H., and Walker, D. (2012). Pharmacokinetics and Metabolism in Drug Design. Weinheim: Wiley VCH.

Srinivasan, R., Henley, B. M., Henderson, B. J., Indersmitten, T., Cohen, B. N., Kim, C. H., et al. (2016). Smoking-relevant nicotine concentration attenuates the unfolded protein response in Dopaminergic neurons. J. Neurosci. 36, 65-79. doi: 10.1523/JNEUROSCI.2126-15.2016

Srinivasan, R., Pantoja, R., Moss, F. J., Mackey, E. D. W., Son, C., Miwa, J., et al. (2011). Nicotine upregulates $\alpha 4 \beta 2$ nicotinic receptors and ER exit sites via stoichiometry-dependent chaperoning. J. Gen. Physiol. 137, 59-79. doi: 10.1085/jgp.201010532

Stenovec, M., Božićs, M., Pirnat, S., and Zorec, R. (2019). Astroglial mechanisms of ketamine action include reduced mobility of Kir4.1-carrying vesicles. Neurochem. Res. doi: 10.1007/s11064-019-02744-1

$\mathrm{Su}$, T.-P. (2019). Non-canonical targets mediating the action of drugs of abuse: cocaine at the Sigma-1 receptor as an example. Front. Neurosci. 13:761. doi: 10.3389/fnins.2019.00761

Tischbirek, C. H., Wenzel, E. M., Zheng, F., Huth, T., Amato, D., Trapp, S., et al. (2012). Use-dependent inhibition of synaptic transmission by the secretion of intravesicularly accumulated antipsychotic drugs. Neuron 74, 830-844. doi: 10.1016/j.neuron.2012.04.019

Trapp, S., Rosania, G. R., Horobin, R. W., and Kornhuber, J. (2008). Quantitative modeling of selective lysosomal targeting for drug design. Eur. Biophys. J. 37, 1317-1328. doi: 10.1007/s00249-008-0338-4

Tucker, K. R., Block, E. R., and Levitan, E. S. (2015). Action potentials and amphetamine release antipsychotic drug from dopamine neuron synaptic VMAT vesicles. Proc. Natl. Acad. Sci. U S A 112, E4485-E4494. doi: $10.1073 /$ pnas. 1503766112
Walters, S. H., and Levitan, E. S. (2019). Vesicular antipsychotic drug release evokes an extra phase of dopamine transmission. Schizophr. Bull. doi: 10.1093/schbul/sbz085

Widman, A. J., and McMahon, L. L. (2018). Disinhibition of CA1 pyramidal cells by low-dose ketamine and other antagonists with rapid antidepressant efficacy. Proc. Natl. Acad. Sci. U S A 115, E3007-E3016. doi: 10.1073/pnas.17188 83115

Wohleb, E. S., Wu, M., Gerhard, D. M., Taylor, S. R., Picciotto, M. R., Alreja, M., et al. (2016). GABA interneurons mediate the rapid antidepressant-like effects of scopolamine. J. Clin. Invest. 126, 2482-2494. doi: 10.1172/jci85033

Wray, N. H., Schappi, J. M., Singh, H., Senese, N. B., and Rasenick, M. M. (2018). NMDAR-independent, cAMP-dependent antidepressant actions of ketamine. Mol. Psychiatry doi: 10.1038/s41380-018-0083-8

Yamakura, T., Chavez-Noriega, L. E., and Harris, R. A. (2000). Subunit-dependent inhibition of human neuronal nicotinic acetylcholine receptors and other ligand-gated ion channels by dissociative anesthetics ketamine and dizocilpine. Anesthesiology 92, 1144-1153. doi: 10.1097/00000542-200004000-00033

Yang, Y., Cui, Y., Sang, K., Dong, Y., Ni, Z., Ma, S., et al. (2018). Ketamine blocks bursting in the lateral habenula to rapidly relieve depression. Nature 554, 317-322. doi: 10.1038/nature25509

Zanos, P., Moaddel, R., Morris, P. J., Riggs, L. M., Highland, J. N., Georgiou, P., et al. (2018). Ketamine and ketamine metabolite pharmacology: insights into therapeutic mechanisms. Pharmacol. Rev. 70, 621-660. doi: 10.1124/pr.117. 015198

Zoncu, R., Efeyan, A., and Sabatini, D. M. (2011). mTOR: from growth signal integration to cancer, diabetes and ageing. Nat. Rev. Mol. Cell Biol. 12, 21-35. doi: $10.1038 / \mathrm{nrm} 3025$

Conflict of Interest: LT is the founder of Seven Biosciences.

The remaining authors declare that the research was conducted in the absence of any commercial or financial relationships that could be construed as a potential conflict of interest.

Copyright (C) 2019 Bera, Kamajaya, Shivange, Muthusamy, Nichols, Borden, Grant, Jeon, Lin, Bishara, Chin, Cohen, Kim, Unger, Tian, Marvin, Looger and Lester. This is an open-access article distributed under the terms of the Creative Commons Attribution License (CC BY). The use, distribution or reproduction in other forums is permitted, provided the original author(s) and the copyright owner(s) are credited and that the original publication in this journal is cited, in accordance with accepted academic practice. No use, distribution or reproduction is permitted which does not comply with these terms. 